\title{
Clinical Study \\ The Incidence and Predictors of Thromboembolic Events in Patients with Lung Cancer
}

\author{
Bohdan Kadlec, ${ }^{1}$ Jana Skrickova, ${ }^{1}$ Zdenek Merta, ${ }^{1}$ Ladislav Dusek, ${ }^{2}$ and Jiri Jarkovsky ${ }^{2}$ \\ ${ }^{1}$ Department of Respiratory Diseases and TB, Faculty of Medicine, Masaryk University and University Hospital, Brno, Czech Republic \\ ${ }^{2}$ Institute of Biostatistics and Analyses, Faculty of Medicine and Faculty of Science, Masaryk University, Brno, Czech Republic \\ Correspondence should be addressed to Jana Skrickova; jskric@fnbrno.cz
}

Received 30 August 2013; Accepted 30 October 2013; Published 20 January 2014

Academic Editors: A. Niemierko and C. A. Perez

Copyright (C) 2014 Bohdan Kadlec et al. This is an open access article distributed under the Creative Commons Attribution License, which permits unrestricted use, distribution, and reproduction in any medium, provided the original work is properly cited.

\begin{abstract}
Patients with lung cancer experience elevated risk of venous thromboembolism. Cancer patients with thrombosis have a shorter life expectancy and the occurrence of VTE worsens the quality of life and may delay, interrupt, or completely halt the cancer therapy. In a large cohort of lung cancer patients we monitored the incidence of venous thromboembolism and we identified groups of patients with the highest risk of venous thromboembolism suitable for antithrombotic prophylaxis, which could favourably affect their morbidity and mortality.
\end{abstract}

\section{Background}

The relationship between thrombosis and cancer is known for quite a long time. It was first broached in 1865 by the French internist Armand Trousseau who described migratory thrombophlebitis as a precursor to cancer (Trousseau's syndrome) [1]. Thromboembolic disorders have a wide spectrum of clinical manifestations. The most common and serious is venous thromboembolism, including pulmonary embolism and deep venous thrombosis. The risk factors for VTE [2] are defined by the still valid theory formulated by the German pathologist Rudolf Virchow more than 150 years ago. The incidence of thromboembolic disease in general population is relatively low, about 1-3 per 1,000 people annually [3]. Among the cancer patients, the occurrence of VTE is 4-7 times higher, depending on the type and the stage of cancer [4]. Of patients who develop thromboembolic disease, $20 \%$ are cancer patients. However, data on the occurrence of VTE in cancer patients is probably underestimated, judging by autopsy findings where pulmonary embolism or venous thrombosis is found in more than $50 \%$ of autopsies [5], while VTE detection in lifetime only amounts to $15 \%$ of cases, indicating substantial shortcomings in diagnosis. The presence of VTE also serves as a negative predictor of survival in cancer patients and increases the probability of their death 2-8 times. Developing thromboembolism complicates cancer treatment and is associated with a significantly poorer prognosis. As results of a large Danish cancer registry are revealed [6], the one-year survival of cancer patients with VTE is $12 \%$, against $36 \%$ in cancer patients without VTE. However, the risk is not the same for all tumors; it is greatest in lymphomas and cancer of brain, lung, pancreas, stomach, ovary and kidney [7]. The risk of thrombosis is also associated with the histological type of tumor, for example, mucinproducing adenocarcinoma (stomach, pancreas, lung, and ovary) [8].

One of the most common manifestations of cancer is hypercoagulation (Table 1). The tendency to hypercoagulation associated with smaller wettability and antithrombotic activity of vascular endothelial cells facilitates the adhesion of circulating tumor cells, which is a prerequisite for further metastatic spread of the tumor [9]. Tumor cells can directly activate blood clotting, inducing procoagulant or suppressing anticoagulant properties of vascular endothelium, platelets, monocytes, and macrophages. Overproduction of procoagulation factors, particularly the tissue factor, also leads to increased production of thrombin [10]. Apart from direct involvement in coagulation and primary hemostasis, thrombogenesis can also be due to distortion by the tumor of vascular endothelium's function and integrity, leading to 
TABLE 1: Prothrombotic mechanisms in tumors.

Proaggregation and procoagulant activity, increased platelet

Acceleration of thrombin production, overproduction of tissue Factor, and other procoagulant factors

Cytokine production by tumor cells, production of TNF-1, interleukin-11, and VEGF

Direct interactions between tumor cells and the endothelium of blood vessels (increased adhesiveness)

Factors related to cancer treatment-surgery, radiotherapy, chemotherapy, and antiangiogenic treatment

Increased immobilization, central venous catheters

activation of coagulation or restriction of blood flow in the vessel oppressed by tumor, with subsequent accumulation of activated clotting factors and platelets. The emergence and growth of thrombus is also supported by such complications of cancer as organ damage, sepsis, changes in the internal environment, and therapeutic interventions directed against cancer (chemotherapy, hormonal therapy, antiangiogenic therapy, and central venous catheters) [11]. General factors such as age, immobilization, and surgery also contribute to the emergence of VTE in cancer patients [12-15]. Laboratory changes include the increase in fibrinogen concentration, reduced clotting times and, quite frequently, thrombocytosis. Thrombocytosis occurs in gastric or colon cancer patients and in lymphoma patients $[16,17]$. The increase in platelets per se does not indicate hypercoagulation, but it can facilitate thrombosis if simultaneous activation of procoagulant factors occurs [18]. Platelets circulate in the inactive state, but upon stimulation by activators (thrombin, prostaglandins, ADP, epinephrine, and other substances produced by tumors) there may be an increase in their spontaneous aggregation and adhesiveness [19].

Deep vein thrombosis and pulmonary embolism are the most important manifestations of thromboembolic disease in cancer patients [20]. Thrombophlebitis migrans, or migratory superficial phlebitis, is less frequent than VTE, but often precedes-even by months-other clinical signs of malignancy. This is mostly observed in patients with pancreatic, breast, prostate, ovarian, and gastric cancer [21].

Disseminated intravascular coagulation associated with bleeding and thrombotic symptoms is a rare manifestation of malignancy, yet it is common in some types of leukemia. In solid tumors, it can be present in advanced stages of the disease [22].

\section{Material and Methods}

Patients diagnosed with primary lung cancer, verified either histologically or cytologically, were recruited at the University Hospital's Department of Pulmonary Diseases and Tuberculosis, Brno, from January 2006 to May 2010. We recorded basic demographic data, data on histology and clinical stage, information about frequent and significant comorbidities, and details of the initial cancer chemotherapy treatment, radiotherapy, targeted therapy, surgery, or best supportive care. Chemotherapy in most cases entailed a combination of platinum derivatives with gemcitabine, paclitaxel, vinorelbine, etoposide, or pemetrexed. Targeted drugs for first-line treatment of advanced nonsmall cell lung cancer were EGFR inhibitors, gefitinib and erlotinib, and angiogenesis inhibitor bevacizumab.

Hematological examinations were performed in the laboratories of the University Hospital's Department of Clinical Hematology in Brno. Laboratory parameters we followed were PT, aPTT, fibrinogen, D-dimers, total number of platelets, and total white blood cell count and hemoglobin. In patients with locoregionally advanced, unresectable or metastatic lung cancer, these parameters were evaluated prior to the first cycle of chemotherapy or targeted therapy. The diagnosis of thromboembolic events was done by standard diagnostic procedures; their risk was summarily determined as high [23].

Descriptive statistics was used for description of the data: absolute and relative frequency of each category for categorical variables; median and 5\%-95\% percentiles for continuous variables. The analysis of categorical variables was supplemented with an analysis of frequency tables.

The differences between levels of hemostatic factors according to various categories were tested by nonparametric Kruskal-Wallis test, which guarantees sufficiently robust results unaffected by outliers or nonnormal distribution of the original data. Relationships between categorical variables and relationships between categories resulting from dividing the patients according to different types of thromboembolic events, were tested by chi-square test of maximum likelihood. The differences in continuous variables between groups of patients were tested by the Mann-Whitney $U$ test and the Kruskal-Wallis test.

In determining the boundaries of hemostatic factors according to occurrence of thromboembolic events, receiver operating characteristic (ROC) analysis was used; its results are described by the area under the ROC curve with $95 \%$ confidence interval, along with the $P$ value of the test for differences from the expected area under the curve of 0.5 .

To analyze the relationship between various patient characteristic traits and the occurrence of thromboembolic events, logistic regression was used; its results are described by the odds ratio, confidence interval, and statistical significance.

All testing was performed at the level of statistical significance of 0.05; calculations were made using the IBM SPSS Statistics 20 program (IBM Corporation, 2011).

\section{Results}

3.1. Description of the Patient Group (Table 2). We included 950 patients -600 men and 350 women. The median age of the patients was 64 years. The most frequently occurring histologic subtype was squamous cell carcinoma (27.5\%), followed by adenocarcinoma (23.8\%), small cell carcinoma (18.4\%), and nonsmall cell without further specification (NOS); the remaining $10 \%$ was less common types such as large cell, sarcomatoid, and mixed carcinoid cancer. In 34 patients (3.6\%), the diagnosis was not confirmed by histology 
TABLE 2: Patient population description.

\begin{tabular}{|c|c|c|}
\hline \multicolumn{3}{|l|}{ Population description } \\
\hline$N=950$ & $N^{1}$ & Value $^{2}$ \\
\hline Sex & 950 & \\
\hline Male & & $600(63.2 \%)$ \\
\hline Female & & $350(36.8 \%)$ \\
\hline Age & 950 & $64.0(42.0-84.0)$ \\
\hline$<50$ & & $153(16.1 \%)$ \\
\hline $50-65$ & & $356(37.5 \%)$ \\
\hline $65-80$ & & $327(34.4 \%)$ \\
\hline$>80$ & & $114(12.0 \%)$ \\
\hline Histology & 950 & \\
\hline Adenocarcinoma & & $226(23.8 \%)$ \\
\hline Squamous cell carcinoma & & $261(27.5 \%)$ \\
\hline Small cell carcinoma & & $175(18.4 \%)$ \\
\hline Large cell carcinoma & & $61(6.4 \%)$ \\
\hline Small cell carcinoma not otherwise specified & & $113(11.9 \%)$ \\
\hline Other & & $80(8.4 \%)$ \\
\hline Not determined & & $34(3.6 \%)$ \\
\hline Clinical stage & 823 & \\
\hline I & & $80(9.7 \%)$ \\
\hline II & & $76(9.2 \%)$ \\
\hline III & & $274(33.3 \%)$ \\
\hline IV & & $393(41.4 \%)$ \\
\hline Initial treatment & 950 & \\
\hline Chemotherapy & & $605(63.7 \%)$ \\
\hline Radiotherapy & & $45(4.7 \%)$ \\
\hline Surgery & & $149(15.7 \%)$ \\
\hline Biological therapy & & $25(2.6 \%)$ \\
\hline Symptomatic treatment & & $126(13.3 \%)$ \\
\hline Smoking & 907 & $799(88.1 \%)$ \\
\hline COPD & 950 & $363(38.2 \%)$ \\
\hline Diabetes mellitus & 950 & $184(19.4 \%)$ \\
\hline Cerebrovascular disease & 950 & $91(9.6 \%)$ \\
\hline Hypertension & 950 & $376(39.6 \%)$ \\
\hline Heart failure & 950 & $73(7.7 \%)$ \\
\hline Atrial fibrillation & 950 & $61(6.4 \%)$ \\
\hline Obesity & 950 & $78(8.2 \%)$ \\
\hline Platelets at the time of diagnosis & 950 & $286.5(107.0-488.0)$ \\
\hline WBC & 950 & $7.0(1.9-12.5)$ \\
\hline Hemoglobin & 950 & $122.0(93.0-154.0)$ \\
\hline $\mathrm{PT}$ & 926 & $1.0(0.7-1.7)$ \\
\hline aPTT & 925 & $34.5(24.6-44.4)$ \\
\hline Fibrinogen & 874 & $3.1(1.8-5.7)$ \\
\hline D-dimers & 811 & $0.4(0.2-0.6)$ \\
\hline Thromboembolic event 6 months after treatment initiation & 950 & $91(9.6 \%)$ \\
\hline Severity of thromboembolic event & 91 & \\
\hline Nonserious & & $11(12.1 \%)$ \\
\hline Serious & & $80(87.9 \%)$ \\
\hline
\end{tabular}

\footnotetext{
${ }^{1}$ Available $N$.
}

${ }^{2}$ Categorical variables are described by absolute and relative frequencies; continuous variables are described by median and 5\%-95\% percentiles. 
TABLE 3: Relationship between potential predictors and occurrence of thromboembolic events.

\begin{tabular}{|c|c|c|c|c|}
\hline$N=950$ & Any VTE & OR $(95 \% \mathrm{CI})^{1}$ & Serious VTE & OR $(95 \% \mathrm{CI})^{1}$ \\
\hline \multicolumn{5}{|l|}{$\operatorname{Sex}(N=950)$} \\
\hline Male & $50(8.3 \%)$ & Reference & $43(7.2 \%)$ & Reference \\
\hline Female & $41(11.7 \%)$ & $1.46(0.94-2.26)$ & $37(10.6 \%)$ & $1.53(0.97-2.43)$ \\
\hline Age & & $1.02(1.00-1.04)^{*}$ & & $1.02(1.00-1.04)^{*}$ \\
\hline \multicolumn{5}{|l|}{ Age categorized $(N=950)$} \\
\hline$<50$ & $11(7.2 \%)$ & Reference & $10(6.5 \%)$ & Reference \\
\hline $50-65$ & $30(8.4 \%)$ & $1.19(0.58-2.44)$ & $24(6.7 \%)$ & $1.03(0.48-2.22)$ \\
\hline $65-80$ & $34(10.4 \%)$ & $1.50(0.74-3.04)$ & $31(9.5 \%)$ & $1.50(0.71-3.14)$ \\
\hline$>80$ & $16(14.0 \%)$ & $2.11(0.94-4.74)$ & $15(13.2 \%)$ & $2.17(0.94-5.02)$ \\
\hline \multicolumn{5}{|l|}{ Histology $(N=950)$} \\
\hline Adenocarcinoma & $37(16.4 \%)$ & $3.79(1.13-12.73)^{*}$ & $32(14.2 \%)$ & $3.19(0.94-10.79)$ \\
\hline Squamous cell carcinoma & $19(7.3 \%)$ & $1.52(0.43-5.30)$ & $18(6.9 \%)$ & $1.43(0.41-5.03)$ \\
\hline Small cell carcinoma & $14(8.0 \%)$ & $1.68(0.47-6.06)$ & $11(6.3 \%)$ & $1.30(0.35-4.81)$ \\
\hline Large cell carcinoma & $3(4.9 \%)$ & Reference & $3(4.9 \%)$ & Reference \\
\hline NSCLC NOS & $9(8.0 \%)$ & $1.67(0.44-6.43)$ & $8(7.1 \%)$ & $1.47(0.38-5.77)$ \\
\hline Other & $6(7.5 \%)$ & $1.57(0.38-6.54)$ & $5(6.3 \%)$ & $1.29(0.30-5.62)$ \\
\hline Not determined & $3(8.8 \%)$ & $1.87(0.36-9.83)$ & $3(8.8 \%)$ & $1.87(0.36-9.83)$ \\
\hline \multicolumn{5}{|l|}{ Clinical stage $(N=823)$} \\
\hline I & $9(11.3 \%)$ & Reference & $7(8.8 \%)$ & Reference \\
\hline II & $11(14.5 \%)$ & $1.34(0.52-3.43)$ & $10(13.2 \%)$ & $1.58(0.57-4.39)$ \\
\hline III & $29(10.6 \%)$ & $0.93(0.42-2.06)$ & $25(9.1 \%)$ & $1.05(0.44-2.52)$ \\
\hline IV & $36(9.2 \%)$ & $0.80(0.37-1.72)$ & $32(8.1 \%)$ & $0.92(0.39-2.18)$ \\
\hline \multicolumn{5}{|l|}{ Initial treatment $(N=950)$} \\
\hline Chemotherapy & $44(7.3 \%)$ & Reference & $39(6.4 \%)$ & Reference \\
\hline Radiotherapy & $10(22.2 \%)$ & $3.64(1.69-7.84)^{*}$ & $9(20.0 \%)$ & $3.63(1.63-8.07)^{*}$ \\
\hline Surgery & $16(10.7 \%)$ & $1.53(0.84-2.80)$ & $13(8.7 \%)$ & $1.39(0.72-2.67)$ \\
\hline Targeted therapy & $3(12.0 \%)$ & $1.74(0.50-6.04)$ & $2(8.0 \%)$ & $1.26(0.29-5.55)$ \\
\hline Symptomatic treatment & $18(9.6 \%)$ & $2.13(1.18-3.82)^{*}$ & $17(13.5 \%)$ & $2.26(1.24-4.15)^{*}$ \\
\hline Smoking $(N=907)$ & $81(10.1 \%)$ & $1.11(0.56-2.20)$ & $71(8.9 \%)$ & $1.07(0.52-2.21)$ \\
\hline $\operatorname{COPD}(N=950)$ & $44(12.1 \%)$ & $1.59(1.03-2.45)^{*}$ & $39(10.7 \%)$ & $1.60(1.01-2.54)^{*}$ \\
\hline Diabetes mellitus $(N=950)$ & $27(14.7 \%)$ & $1.89(1.17-3.05)^{*}$ & $25(13.6 \%)$ & $2.03(1.23-3.36)^{*}$ \\
\hline Cerebrovascular disease $(N=950)$ & $20(22.0 \%)$ & $3.13(1.80-5.43)^{*}$ & $18(19.8 \%)$ & $3.17(1.78-5.64)^{*}$ \\
\hline Hypertension $(N=950)$ & $54(14.4 \%)$ & $2.43(1.57-3.78)^{*}$ & $49(13.0 \%)$ & $2.63(1.64-4.20)^{*}$ \\
\hline Hearth failure $(N=950)$ & $32(43.8 \%)$ & $10.82(6.35-18.43)^{*}$ & $32(43.8 \%)$ & $13.48(7.80-23.28)^{*}$ \\
\hline Atrial fibrillation $(N=950)$ & $13(21.3 \%)$ & $2.82(1.46-5.42)^{*}$ & $12(19.7 \%)$ & $2.96(1.50-5.83)^{*}$ \\
\hline Obesity $(N=950)$ & $14(17.9 \%)$ & $2.26(1.21-4.21)^{*}$ & $13(16.7 \%)$ & $2.40(1.26-4.58)^{*}$ \\
\hline Platelets at the time of diagnosis $(N=950)$ & & $1.01(1.00-1.01)^{*}$ & & $1.01(1.00-1.01)^{*}$ \\
\hline PLT $>299.5$ & $68(15.5 \%)$ & $3.89(2.38-6.36)^{*}$ & - & - \\
\hline PLT > 330.5 & - & - & $54(14.6 \%)$ & $3.66(2.25-5.96)^{*}$ \\
\hline $\mathrm{WBC}(N=950)$ & & $0.92(0.86-0.99)^{*}$ & & $0.93(0.86-0.99)^{*}$ \\
\hline $\mathrm{WBC}<6.36$ & $51(12.9 \%)$ & $1.92(1.24-2.97)^{*}$ & $43(10.9 \%)$ & $1.72(1.09-2.72)^{*}$ \\
\hline Hemoglobin $(N=950)$ & & $0.99(0.98-1.00)$ & & $0.99(0.98-1.00)$ \\
\hline Hemoglobin $<123.5$ & $53(10.3 \%)$ & $1.20(0.78-1.87)$ & $46(8.9 \%)$ & $1.16(0.73-1.85)$ \\
\hline $\mathrm{PT}(N=926)$ & & $0.96(0.49-1.86)$ & & $0.89(0.43-1.83)$ \\
\hline $\mathrm{PT}<1.05$ & $48(9.8 \%)$ & $1.10(0.70-1.71)$ & $43(8.7 \%)$ & $1.16(0.73-1.87)$ \\
\hline $\operatorname{aPTT}(N=925)$ & & $1.02(0.99-1.06)$ & & $1.03(0.99-1.07)$ \\
\hline $\mathrm{aPTT}>35.95$ & $45(11.7 \%)$ & $1.59(1.02-2.47)^{*}$ & $41(10.7 \%)$ & $1.74(1.08-2.78)^{*}$ \\
\hline Fibrinogen $(N=874)$ & & $1.08(0.90-1.28)$ & & $1.09(0.91-1.31)$ \\
\hline Fibrinogen $>3.15$ & $47(11.2 \%)$ & $1.52(0.96-2.41)$ & - & - \\
\hline
\end{tabular}


TABLe 3: Continued.

\begin{tabular}{ccccc}
\hline$N=950$ & Any VTE & OR $(95 \% \text { CI })^{1}$ & Serious VTE & OR $(95 \% \text { CI })^{1}$ \\
\hline Fibrinogen $>3.35$ & - & - & $37(10.0 \%)$ & $1.48(0.91-2.40)$ \\
D dimers $(N=811)$ & & $0.97(0.82-1.15)$ & - & $0.97(0.81-1.17)$ \\
D dimers $>0.40$ & $32(11.9 \%)$ & $1.65(1.01-2.69)^{*}$ & - \\
D dimers $>0.38$ & - & - & $31(9.2 \%)$ & $1.41(0.84-2.36)$ \\
\hline
\end{tabular}

${ }^{1}$ Logistical regression.

* Statistically significant value OR $(P<0.05)$.

or cytology. Representation of different clinical stages was similar to that in the general population; that is, most patients had advanced stages III (33.3\%) and IV (41.4\%) while clinical stages I and II were relatively less common ( $9.7 \%$ and $9.2 \%$, resp.). Most patients were smokers or ex-smokers $(88.1 \%)$, only $11.9 \%$ nonsmokers. Among comorbidities, hypertension was most frequent (39.6\%), followed by COPD (38.2\%), diabetes mellitus (19.4\%), cerebrovascular disease $9.6 \%$, and heart failure $(7.7 \%)$.

3.2. The Incidence of Thromboembolic Events. Among 950 patients, we found 91 thromboembolic events (9.6\%), of which $80(87.9 \%)$ were serious and $11(12.1 \%)$ less serious. We recorded 34 cases of pulmonary embolism, 58 cases of deep venous thrombosis, and 13 cases with simultaneous occurrence of both diseases. Also found were 11 cases of superficial thrombophlebitis, which were rated as less serious. The most common sources of venous thrombosis were lower limbs (49,74\%) and superior vena cava (5, 11\%); less frequent was thrombosis associated with implantable ports and venous catheters $(3,6 \%)$, while other sources (superior vena cava and subclavian vein) were rarely encountered.

3.3. Hemostatic Parameters. Plasma levels of hemostatic factors had no significant dependence on gender, histology, clinical stage, or smoking; only the age over 65 years appears to be statistically significant. As to comorbidities, statistically increased values of median platelet count were found in patients with COPD-304 $\times 109(115.0-497.0) P=0.031$ and heart failure $340 \times 109(149.0-522.0) P=0.020$. In the group of patients with thromboembolic events, significantly higher levels of platelet count were found at the time of diagnosis of lung cancer-368.0 (191.0-540.0) $P<0.001$ (Figure 2); also significantly higher was the median value of WBC 6.0 $\times 109(2,3-10,7), P=0.017$. On the contrary, median values of PT, aPTT, fibrinogen, or D-dimers were not significantly increased.

3.4. Characteristic of Patients according to the Occurrence of Thromboembolic Events. When comparing groups of patients according to the occurrence of thromboembolic events, we found statistically significant proportion of adenocarcinomas in patients with thromboembolic events - 37 (40.7\%) $P=$ 0.02 , a smaller proportion of squamous cell carcinomas19 (20.9\%), and small cell carcinomas-14 (15.4\%). Among treatment modalities, the highest incidence of thromboembolic events had patients undergoing radiotherapy-10 (11\%),

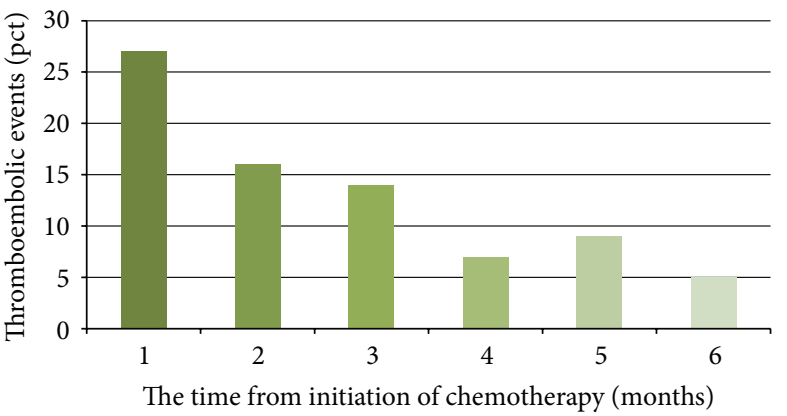

FIGURE 1: The occurrence of thromboembolic events after the start of chemotherapy.

surgery-16 (17.6\%) and chemotherapy 44 (48.4\%). In the group of patients with thromboembolic events we detected a significantly higher proportion of patients with COPD44 (48.4\%) $P=0.038$, diabetes mellitus -27 (29\%) $P=$ 0.013 , cerebrovascular disease-20 (22\%) $P<0.001$, hypertension-54 (29.3\%) $P<0.001$, heart failure-32 (35.2\%) $P<0.001$, atrial fibrillation-13 (14.3\%) $P=0.004$, and obesity-14 (15.4\%) $P=0.017$.

3.5. Predictors of Thromboembolic Events. Statistical analysis of results (Table 3 ) reveals age as a major risk factor for thromboembolic events in patients with lung cancer. In patients aged $50-65$ years, OR is 1.19 (0.158 to 2.44$)$, in patients aged $>65$ years, OR is 1.50 ( 0.74 to 3.04$)$, and in those aged over 80 years, OR is 2.11 ( 0.94 to 4.74$)$. Other significant predictors of VTE are adenocarcinomas-OR 3.79 (1.13 to 12.73), and radiotherapy-OR 3.64 (1.69 to 7.84). Among comorbidities, heart failure was identified as most risky for development of thromboembolic events-OR 13.48 (7.80 to 23.28), followed by cerebrovascular disease-OR 3.17 (1.78 to 5.64), atrial fibrillation-OR 2.96 (1.50 to 5.83), and obesity-OR 2.40 (1.26 to 4.58). Among monitored laboratory parameters, platelet count above $330.5 \times 109$ was associated with OR for major thromboembolic events was 3.66 (2.25 to 5.96) - a statistically significant value (Table 4). OR for D-dimer levels $>0.4 \mathrm{mg} / \mathrm{L}$ was found to be 1.65 (1.01 to 2.69) and OR for aPTT > 35.95 was 1.74 (1.088 to 2.79).

3.6. Evaluation of Patients with Thromboembolic Disease at the Time of Chemotherapy Initiation. The evaluated data shows that the majority of thromboembolic events in patients with lung cancer undergoing chemotherapy occur within 6 months of its initiation (Figure 1). 
TABLE 4: Hemostatic factors "cut-offs" for venous thromboembolic events.

\begin{tabular}{lcccccccccc}
\hline & & \multicolumn{3}{c}{ Any VTE } & & \multicolumn{3}{c}{ Serious VTE } \\
& AUC $(95 \% \mathrm{CI})^{1}$ & $P$ & Sensitivity & Specificity & Cutoff & AUC $(95 \% \mathrm{CI})^{1}$ & $P$ & Sensitivity & Specificity & Cut Off \\
\hline Platelets & $0.68(0.63-0.74)$ & $<0.001$ & 0.747 & 0.568 & 299.5 & $0.69(0.63-0.75)$ & $<0.001$ & 0.675 & 0.638 & 330.5 \\
WBC & $0.58(0.52-0.63)$ & 0.017 & 0.560 & 0.602 & 6.36 & $0.57(0.51-0.63)$ & 0.042 & 0.538 & 0.598 & 6.36 \\
Hemoglobin & $0.54(0.48-0.61)$ & 0.180 & 0.582 & 0.463 & 123.5 & $0.54(0.47-0.61)$ & 0.261 & 0.575 & 0.462 & 123.5 \\
PT & $0.51(0.44-0.57)$ & 0.835 & 0.552 & 0.487 & 1.05 & $0.51(0.44-0.58)$ & 0.751 & 0.566 & 0.488 & 1.05 \\
aPTT & $0.54(0.48-0.61)$ & 0.194 & 0.517 & 0.597 & 35.95 & $0.55(0.48-0.62)$ & 0.148 & 0.539 & 0.597 & 35.95 \\
Fibrinogen & $0.53(0.46-0.60)$ & 0.435 & 0.573 & 0.532 & 3.15 & $0.53(0.45-0.60)$ & 0.480 & 0.514 & 0.584 & 3.35 \\
D dimers & $0.56(0.48-0.63)$ & 0.117 & 0.438 & 0.679 & 0.40 & $0.54(0.46-0.63)$ & 0.249 & 0.492 & 0.592 & 0.38 \\
\hline
\end{tabular}

${ }^{1}$ ROC analysis.
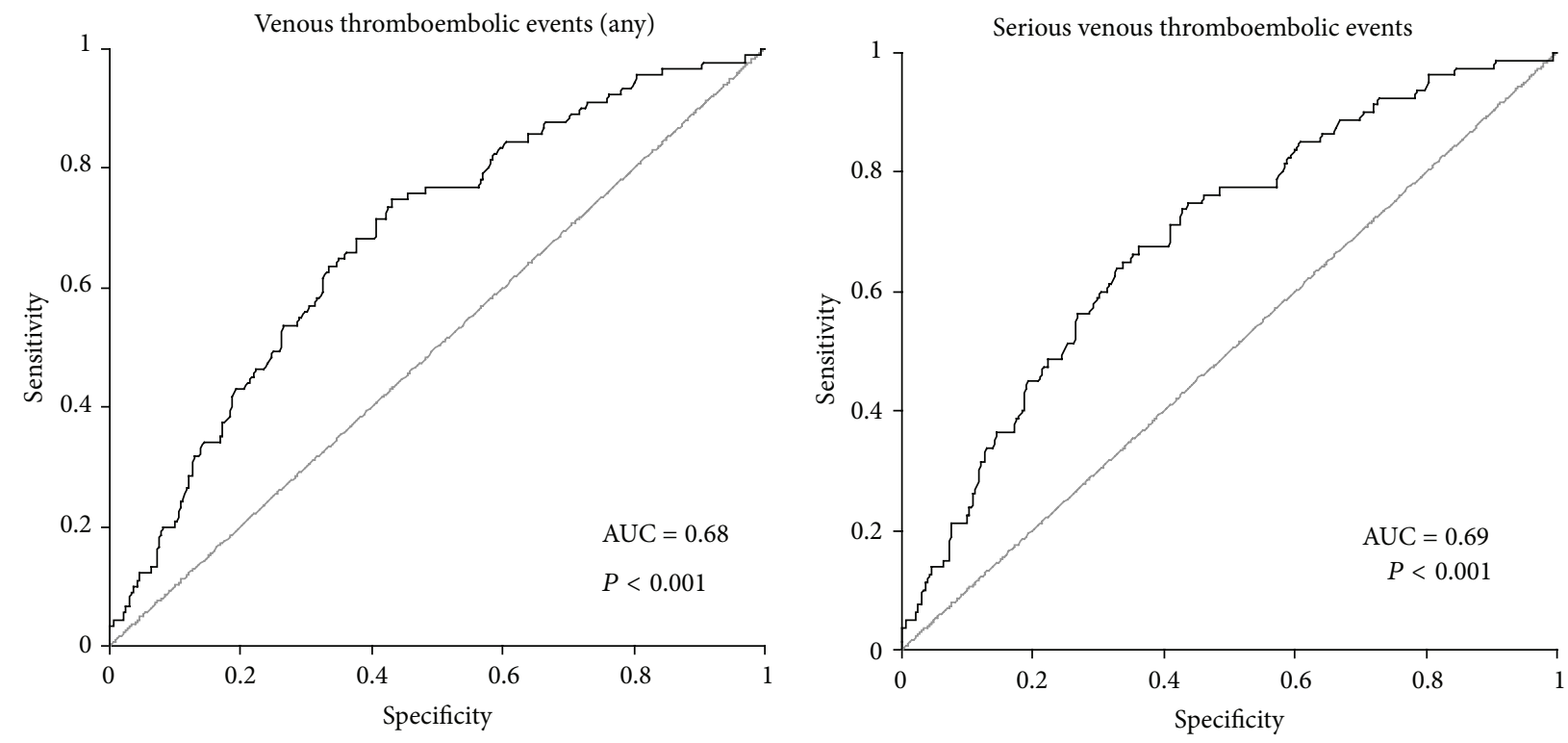

FigURE 2: ROC analysis of the relationship between platelets and thromboembolic events.

\section{Discussion}

In a large cohort of lung cancer patients, we observed a high incidence of VTE- $8.4 \%$, and we identified a number of risk factors: advanced stage of disease, adenocarcinoma, and comorbidities such as heart failure, atrial fibrillation, and cerebrovascular disease. The adjusted incidence rate is 21 cases per 1,000 people per year, which is at least seven times more than the incidence in the general population. This exceeds the incidence reported in previously published studies [7, 24], probably due to the higher number of complicated patients with advanced disease referred to the University Hospital. Improved methods of diagnosis can likewise contribute to the increased incidence.

Adenocarcinomas were associated with twofold increase of risk of VTE compared with squamous-cell carcinomas, a finding consistent with previously published data $[25,26]$. In these studies, mucin-producing adenocarcinoma of the lung was associated with the highest risk of VTE; it is assumed that the presence of mucus may lead to increased secretion of procoagulant factors [27]. There is some evidence that mucin activates platelets and causes microthrombi to form in capillary circulation [26].
We found that in lung cancer patients advanced disease was a significant independent predictor of VTE, the incidence of thromboembolic events in patients with locoregional advanced or metastatic disease being nearly four times higher than in patients in early stages of the disease. This finding is supported by previously published data $[5,28]$.

An increased incidence of thromboembolic events was associated with the increased number of serious comorbidities (especially heart failure, atrial fibrillation, cerebrovascular diseases, and COPD). Similar trends were repeatedly described in noncancer populations $[29,30]$.

Elevated platelet count was shown to be another significant predictor of VTE in our group of patients associated with an increased risk of thromboembolic disease. Thrombocytosis was found in patients with advanced disease, more commonly in men, with no apparent correlation with the clinical stage of the disease [31].

No association was found between increased levels of D-dimer and other coagulation parameters monitored at the time of diagnosis in our patients. Pirk and colleagues found elevated plasma levels of D-dimer associated with an increased risk of death. The risk of death in patients with elevated D-dimer levels was independently increased in 
different subsets of patients, which is consistent with previous observations in small studies conducted in patients with cancer of breast [32,33], colon [34, 35], and lung [36-38]. Relationship between elevated levels of D-dimer and poor prognosis of cancer patients was observed in hematologic malignancies and solid tumors, which is remarkable because high D-dimer was described as a predictor of VTE in earlier works. This shows that an increased activation of coagulation and fibrinolysis, as reflected in high D-dimer levels, is independently associated with poor prognosis and does not necessarily indicate an increased risk of VTE in patients with elevated D-dimer levels [39, 40].

Zecchina and colleagues [41], who investigated the activation of the hemostatic factors in 45 patients with advanced lung cancer in a prospective study, found several other mechanisms increasing the risk of thrombosis in patients with lung cancer. While there were no significant changes in such parameters as D-dimer, fibrinogen, and activated protein $\mathrm{C}$, a significant increase in platelet count was found 21 days after the administration of chemotherapy, correlating with the occurrence of VTE. Another clinical study showed that patients with lung cancer had significantly higher levels of thrombin-antithrombin complexes III, D-dimer, and plasmin-alpha 1-antiplasmin complexes compared with nonmalignant populations, suggesting an increased activation of coagulation and fibrinolysis [42]. Elevated levels of procoagulant factors, such as lupus anticoagulant, anticardiolipin antibodies to factor VIII, and certain cytokines such as interleukin- 6 and tumor necrosis factor, have also been identified as increased risk factors for VTE in patients with lung cancer [43].

Callander et al. [44] and Ornstein with coworkers [45] made an important finding that nonsmall cell lung carcinomas-squamous tumors and even adenocarcinomas-produced tissue factor (TF). Sato et al. [46] described a female patient with adenocarcinoma of the lung where tissue factor played a crucial role in the pathogenesis of recurrent VTE. In her case, plasma levels of TF were significantly elevated. Also, it was demonstrated that cancer cells contained TF factor, as evidenced by staining of tumor tissue using monoclonal antibodies-suggesting that cancer cells themselves could release TF into the circulation.

Khorana and colleagues [47] analyzed the data in a prospective, multicenter study of 3,003 cancer patients receiving at least one cycle of chemotherapy. VTE was found in 58 patients $(1.93 \%)$, with the highest incidence of VTE in tumors of gastrointestinal tract $(2.3 \% /$ month $)$ and lung cancer $(1.2 \% /$ month). An important finding was that the elevation of platelet levels before the start of chemotherapy was associated with a threefold increase in the incidence of VTE. In a multivariate analysis, the increased level of platelets prior to chemotherapy was statistically significantly associated with VTE. The majority of thromboembolic events occurred shortly after the initiation of chemotherapy; $18.1 \%$ of VTE occurred in the first month of chemotherapy, $47 \%$ within the first three months, and $72.5 \%$ within the first six months. These findings suggest that prevention of thrombosis should be considered in lung cancer patients undergoing chemotherapy who have elevated platelet levels.
In the treatment of lung cancer, recent years have seen a remarkable boom of targeted therapy, focused mainly on the EGFR inhibition with erlotinib and gefitinib, and neoangiogenesis inhibition with VEGF inhibitor bevacizumab. Data from clinical studies indicate that the use of angiogenesis inhibitors is associated with an increased incidence of VTE, but also with an increased incidence of bleeding. In our sample, the total number of patients treated with targeted (biological) therapy was too small to allow assessment of statistical significance. Combined modality treatment consisting of chemotherapy, radiotherapy, and the antiangiogenic agent thalidomide led in NSCLC patients to excessive toxicity as well as a higher incidence of thromboembolic events [48], as already seen in previous studies in other malignancies. Yoon and coworkers [49] reported that chemotherapy with bevacizumab, irinotecan, 5-fluorouracil, and leucovorin was associated with a high incidence of thromboembolism.

\section{Conclusion}

The observed incidence (8.4\%) of serious thromboembolic events in patients with lung cancer is high, and it is even significantly higher in patients with nonsmall cell carcinomas, particularly in adenocarcinomas. Most thromboembolic events occurred in patients with advanced stage of the disease and in patients with comorbidities, especially heart failure. In patients with thromboembolic events we found significantly higher median platelet counts at the time of cancer diagnosis; with platelet count above $330,5 \times 109$, the odds ratio of severe VTE was 3.66 (2.25-5.96). Among comorbidities, heart failure was associated with the highest risk for development of VTE-OR 13.48 (7.80-23.28), followed by cerebrovascular disease-OR 3.17 (1.78-5.64), and atrial fibrillation-OR 2.96 (1.50-5.83). In patients with lung cancer, we did not find significantly higher medians of coagulation parameters (Ddimer, fibrinogen, thrombin time, and aPTT). In patients treated with chemotherapy, most VTE were observed shortly after treatment's inception $(26.4 \%$ in the first month, with a gradually declining trend). The majority of thromboembolic events occurred within 6 months from the initiation of chemotherapy.

\section{Abbreviations}

aPTT: Activated partial thromboplastin time

ADP: Adenosine diphosphate

AT: Antithrombin

CI: Confidence interval

CNS: Central nervous system

EGFR: Receptor for epidermal growth factor

DVT: Deep vein thrombosis

OR: Odds ratio

PC: Protein C

PE: Pulmonary embolism

PT: Prothrombin time

ROC: (Receiver operating characteristic) curve is based on a pivot table right, respectively, wrong classification of positive or negative sample 
SCLC: Small cell lung cancer

NSCLC: Nonsmall cell lung cancer

NOS: $\quad$ Not otherwise specified

RF: $\quad$ Risk factor

RR: $\quad$ Relative risk

VTE: Venous thromboembolism.

\section{Conflict of Interests}

The authors declare that there is no conflict of interests regarding the publication of this paper.

\section{References}

[1] A. Trousseau, Phlegmasia Alba Dolens, Clinique Medicale de l'Hotel Dieu de Paris, London, UK, 1865.

[2] J. Leclerc, Venous Thromboembolic Disorders, Lea \& Febiger, Philadelphia, Pa, USA, 1991.

[3] M. Nordstrom, B. Lindblad, D. Bergqvist, and T. Kjellstrom, "A prospective study of the incidence of deep-vein thrombosis within a defined urban population," Journal of Internal Medicine, vol. 232, no. 2, pp. 155-160, 1992.

[4] A. Falanga, "The incidence and risk of venous thromboembolism associated with cancer and nonsurgical cancer treatment," Cancer Investigation, vol. 27, no. 1, pp. 105-115, 2009.

[5] P. D. Stein, A. Beemath, F. A. Meyers, E. Skaf, J. Sanchez, and R. E. Olson, "Incidence of venous thromboembolism in patients hospitalized with cancer," American Journal of Medicine, vol. 119, no. 1, pp. 60-68, 2006.

[6] J. W. Blom, J. P. M. Vanderschoot, M. J. Oostindiër, S. Osanto, F. J. M. Van Der Meer, and F. R. Rosendaal, "Incidence of venous thrombosis in a large cohort of 66329 cancer patients: Results of a record linkage study," Journal of Thrombosis and Haemostasis, vol. 4, no. 3, pp. 529-535, 2006.

[7] A. A. Khorana, C. W. Francis, E. Culakova, N. M. Kuderer, and G. H. Lyman, "Frequency, risk factors, and trends for venous thromboembolism among hospitalized cancer patients," Cancer, vol. 110, no. 10, pp. 2339-2346, 2007.

[8] G. H. Sack Jr., J. Levin, and W. R. Bell, “Trousseau's syndrome and other manifestations of chronic disseminated coagulopathy in patients with neoplasms: clinical, pathophysiologic, and therapeutic features," Medicine, vol. 56, no. 1, pp. 1-37, 1977.

[9] C. Boccaccio and P. M. Comoglio, "Genetic link between cancer and thrombosis," Journal of Clinical Oncology, vol. 27, no. 29, pp. 4827-4833, 2009.

[10] M. Penka, "Aktivace krevního srážení u onkologicky nemocných," Vnitřní Lékařství, vol. 43, pp. 337-339, 1997.

[11] A. Varki, "Trousseau's syndrome: multiple definitions and multiple mechanisms," Blood, vol. 110, no. 6, pp. 1723-1729, 2007.

[12] S. R. Deitcher, "Cancer-related deep venous thrombosis: clinical importance, treatment challenges, and management strategies," Seminars in Thrombosis and Hemostasis, vol. 29, no. 3, pp. 247258, 2003.

[13] J. Hammond, C. Kozma, J. C. Hart et al., "Rates of venous thromboembolism among patients with major surgery for cancer," Annals of Surgical Oncology, vol. 18, no. 12, pp. 32403247, 2011.

[14] T. C. Haddad and E. W. Greeno, "Chemotherapy induced thrombosis," Thrombosis Research, vol. 118, pp. 555-568, 2006.
[15] S. R. Deitcher and M. P. V. Gomes, "The risk of venous thromboembolic disease associated with adjuvant hormone therapy for breast carcinoma: a systematic review," Cancer, vol. 101, no. 3, pp. 439-449, 2004.

[16] A. I. Schafer, "Thrombocytosis," The New England Journal of Medicine, vol. 350, pp. 1211-1219, 2004.

[17] K. Kaushansky, "The molecular mechanisms that control thrombopoiesis," Journal of Clinical Investigation, vol. 115, no. 12, pp. 3339-3347, 2005.

[18] K. Kaushansky, "On the molecular origins of the chronic myeloproliferative disorders: it all makes sense," Blood, vol. 105, no. 11, pp. 4187-4190, 2005.

[19] A. I. Schafer, "Molecular basis of the diagnosis and treatment of polycythemia vera and essential thrombocythemia," Blood, vol. 107, no. 11, pp. 4214-4222, 2006.

[20] G. Maynard and J. Stein, Preventing Hospitalacquired Venous Thromboembolism: A Guide for Effective Quality Improvement, Prepared for the Society of Hospital Medicine. AHRQ Publication No. 08-0075, Agency for Healthcare Research and Quality, Rockville, Md, USA, 2008.

[21] M. O. Mate-Kole and K. Nkrumah, "Thrombophlebitis migrans as a marker of malignancy," East African Medical Journal, vol. 63, no. 9, pp. 610-612, 1986.

[22] F. Langer, B. Spath, K. Haubold et al., “Tissue factor procoagulant activity of plasma microparticles in patients with cancerassociated disseminated intravascular coagulation," Annals of Hematology, vol. 87, no. 6, pp. 451-457, 2008.

[23] E. J. Favaloro, "Diagnostic issues in thrombophilia: a laboratory scientist's view," Seminars in Thrombosis and Hemostasis, vol. 31, no. 1, pp. 11-16, 2005.

[24] J. Widimský and J. Malý, Akutní Plicní Embolie a Žilní Trombóza. Patogeneze, Diagnostika, Léčba a Prevence. 3. Rozšírené a Přepracované Vydání, Triton, Praha, Czech Republic, 2011.

[25] J. Widimský, J. Malý, P. Eliáš, O. Lang, P. Franc, and K. Roztočil, "Doporučení diagnostiky, léčby a prevence plicní embolie," verze, Praha, 2011, http://www.kardio-cz.cz/resources/.

[26] H. K. Chew, A. M. Davies, T. Wun, D. Harvey, H. Zhou, and R. $\mathrm{H}$. White, "The incidence of venous thromboembolism among patients with primary lung cancer," Journal of Thrombosis and Haemostasis, vol. 6, no. 4, pp. 601-608, 2008.

[27] H. K. Chew, A. M. Davies, T. Wun, D. Harvey, H. Zhou, and R. $\mathrm{H}$. White, "The incidence of venous thromboembolism among patients with primary lung cancer," Journal of Thrombosis and Haemostasis, vol. 6, no. 4, pp. 601-608, 2008.

[28] J. W. Blom, S. Osanto, and F. R. Rosendaal, "The risk of a venous thrombotic event in lung cancer patients: higher risk for adenocarcinoma than squamous cell carcinoma," Journal of Thrombosis and Haemostasis, vol. 2, no. 10, pp. 1760-1765, 2004.

[29] M. F. Loreto, M. De Martinis, M. P. Corsi, M. Modesti, and L. Ginaldi, "Coagulation and cancer: implications for diagnosis and management," Pathology and Oncology Research, vol. 6, no. 4, pp. 301-312, 2000.

[30] H. K. Chew, T. Wun, D. Harvey, H. Zhou, and R. H. White, "Incidence of venous thromboembolism and its effect on survival among patients with common cancers," Archives of Internal Medicine, vol. 166, no. 4, pp. 458-464, 2006.

[31] S. Haas, "Venous thromboembolism in medical patients-the scope of the problem," Seminars in Thrombosis and Hemostasis, vol. 29, supplement 1, pp. 17-21, 2003. 
[32] R. Alikhan, A. T. Cohen, S. Combe et al., "Risk factors for venous thromboembolism in hospitalized patients with acute medical illness: analysis of the MEDENOX Study," Archives of Internal Medicine, vol. 164, no. 9, pp. 963-968, 2004.

[33] N. Y. Demirci, Ü. Y. Turay, A. Yılmaz, Y. Erdogan, Ç. Biber, and H. Yücel, "Vascular events in lung cancer," Asian Pacific Journal of Cancer Prevention, vol. 12, no. 10, pp. 2685-2687, 2011.

[34] K. Blackwell, Z. Haroon, G. Broadwater et al., "Plasma Ddimer levels in operable breast cancer patients correlate with clinical stage and axillary lymph node status," Journal of Clinical Oncology, vol. 18, no. 3, pp. 600-608, 2000.

[35] A. P. B. Batschauer, C. P. Figueiredo, E. C. Bueno et al., "D-dimer as a possible prognostic marker of operable hormone receptornegative breast cancer," Annals of Oncology, vol. 21, no. 6, pp. 1267-1272, 2009.

[36] M. Oya, Y. Akiyama, T. Okuyama, and H. Ishikawa, "High preoperative plasma D-dimer level and short survival after curative resection in patients with colorectal cancer," Japanese Journal of Clinical Oncology, vol. 31, no. 8, pp. 388-394, 2001.

[37] K. Blackwell, H. Hurwitz, G. Liebérman et al., "Circulating Ddimer levels are better predictors of overall survival and disease progression than carcinoembryonic antigen levels in patients with metastatic colorectal carcinoma," Cancer, vol. 101, no. 1, pp. 77-82, 2004.

[38] G. Altiay, A. Ciftci, M. Demir et al., "High plasma d-dimer level is associated with decreased survival in patients with lung cancer," Clinical Oncology, vol. 19, no. 7, pp. 494-498, 2007.

[39] G. Buccheri, P. Torchio, and D. Ferrigno, "Plasma levels of Ddimer in lung carcinoma: clinical and prognostic significance," Cancer, vol. 97, no. 12, pp. 3044-3052, 2003.

[40] O. Taguchi, E. C. Gabazza, H. Yasui, T. Kobayashi, M. Yoshida, and H. Kobayashi, "Prognostic significance of plasma D-dimer levels in patients with lung cancer," Thorax, vol. 52, no. 6, pp. 563-565, 1997.

[41] G. Zecchina, P. Ghio, S. Bosio, M. Cravino, C. Camaschella, and G. V. Scagliotti, "Reactive thrombocytosis might contribute to chemotherapy-related thrombophilia in patients with lung cancer," Clinical Lung Cancer, vol. 8, no. 4, pp. 264-267, 2007.

[42] E. C. Gabazza, O. Taguchi, T. Yamakami, M. Machishi, H. Ibata, and S. Suzuki, "Evaluating prethrombotic state in lung cancer using molecular markers," Chest, vol. 103, no. 1, pp. 196-200, 1993.

[43] E. De Meis, V. R. Pinheiro, M. M. Zamboni et al., "Clotting, immune system, and venous thrombosis in lung adenocarcinoma patients: A prospective study," Cancer Investigation, vol. 27, no. 10, pp. 989-997, 2009.

[44] N. S. Callander, N. Varki, and L. V. M. Rao, "Immunohistochemical identification of tissue factor in solid tumors," Cancer, vol. 70, no. 5, pp. 1194-1201, 1992.

[45] D. L. Ornstein, L. R. Zacharski, V. A. Memoli et al., "Coexisting macrophage associated fibrin formation and tumor cell urokinase in squamous cell and adenocarcinoma of the lung tissues," Cancer, vol. 68, pp. 1061-1067, 1991.

[46] T. Sato, I. Tsujino, D. Ikeda, M. Ieko, and M. Nishimura, "Trousseau's syndrome associated with tissue factor produced by pulmonary adenocarcinoma," Thorax, vol. 61, no. 11, pp. 1009-1010, 2006.

[47] A. A. Khorana, C. W. Francis, E. Culakova, and G. H. Lyman, "Risk factors for chemotherapy-associated venous thromboembolism in a prospective observational study," Cancer, vol. 104, no. 12, pp. 2822-2829, 2005.
[48] M. S. Anscher, J. Garst, L. B. Marks et al., "Assessing the ability of the antiangiogenic and anticytokine agent thalidomide to modulate radiation-induced lung injury," International Journal of Radiation Oncology Biology Physics, vol. 66, no. 2, pp. 477482, 2006.

[49] S. Yoon, D. Schmassmann-Suhijar, M. Zuber, P. Konietzny, and A. Schmassmann, "Chemotherapy with bevacizumab, irinotecan, 5-fluorouracil and leucovorin (IFL) associated with a large, embolizing thrombus in the thoracic aorta," Annals of Oncology, vol. 17, no. 12, pp. 1851-1852, 2006. 


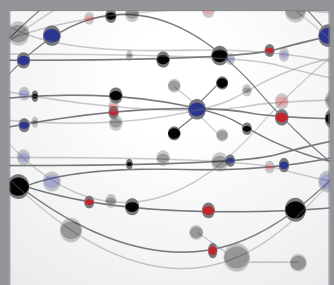

The Scientific World Journal
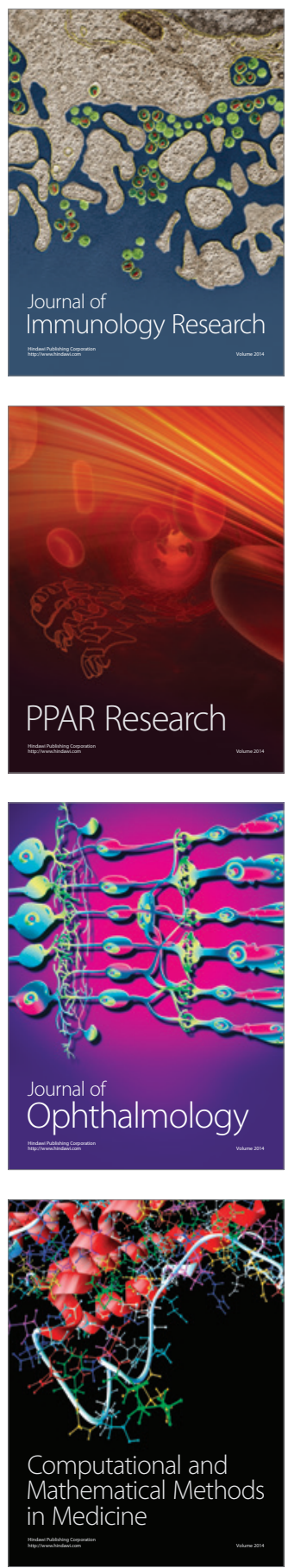

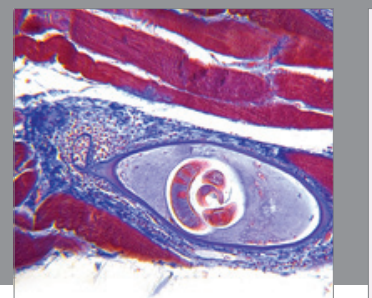

Gastroenterology

Research and Practice
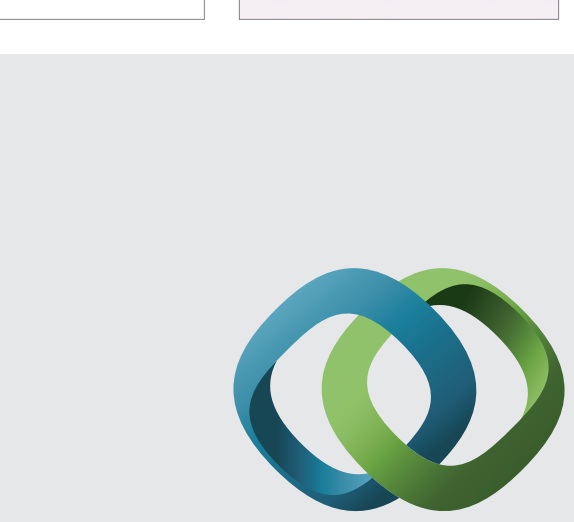

\section{Hindawi}

Submit your manuscripts at

http://www.hindawi.com
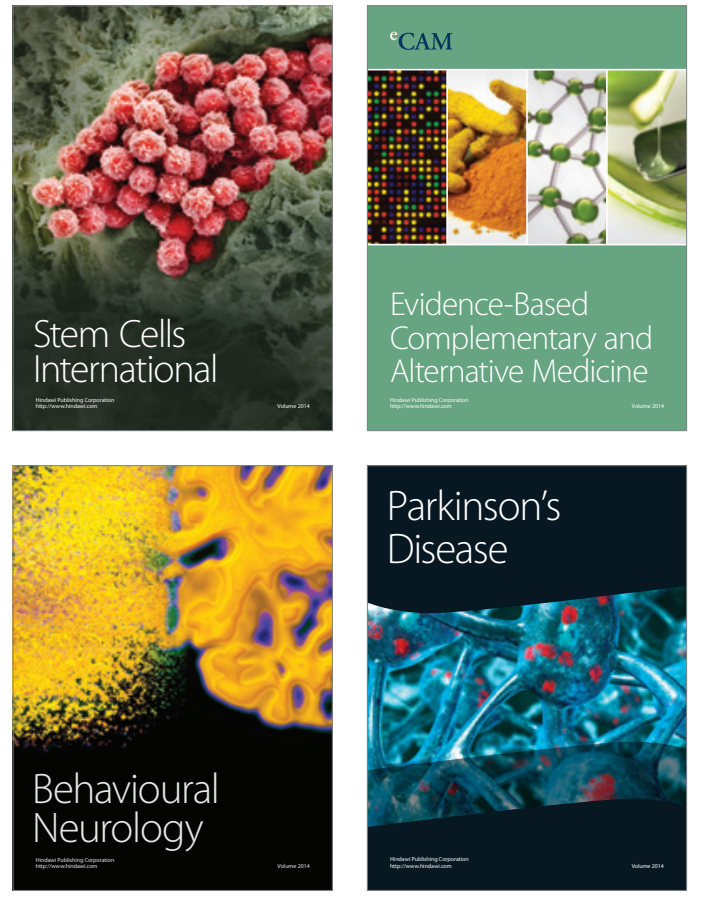
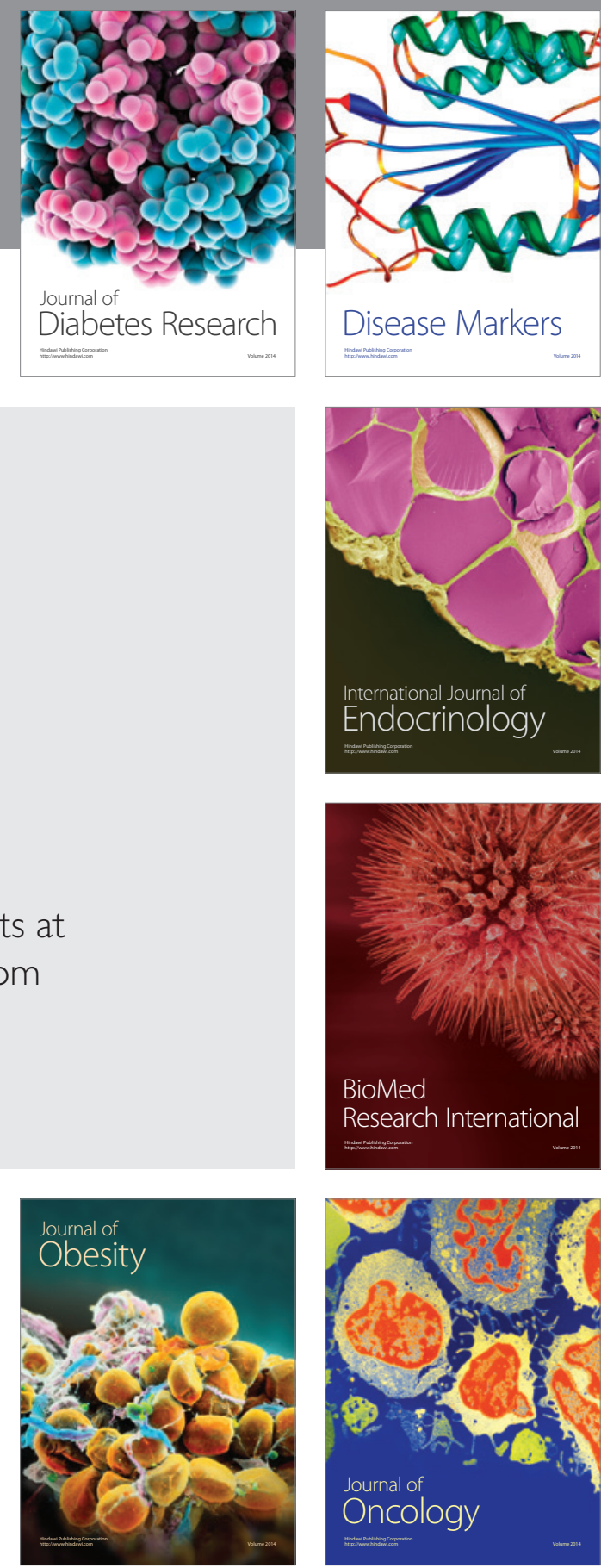

Disease Markers
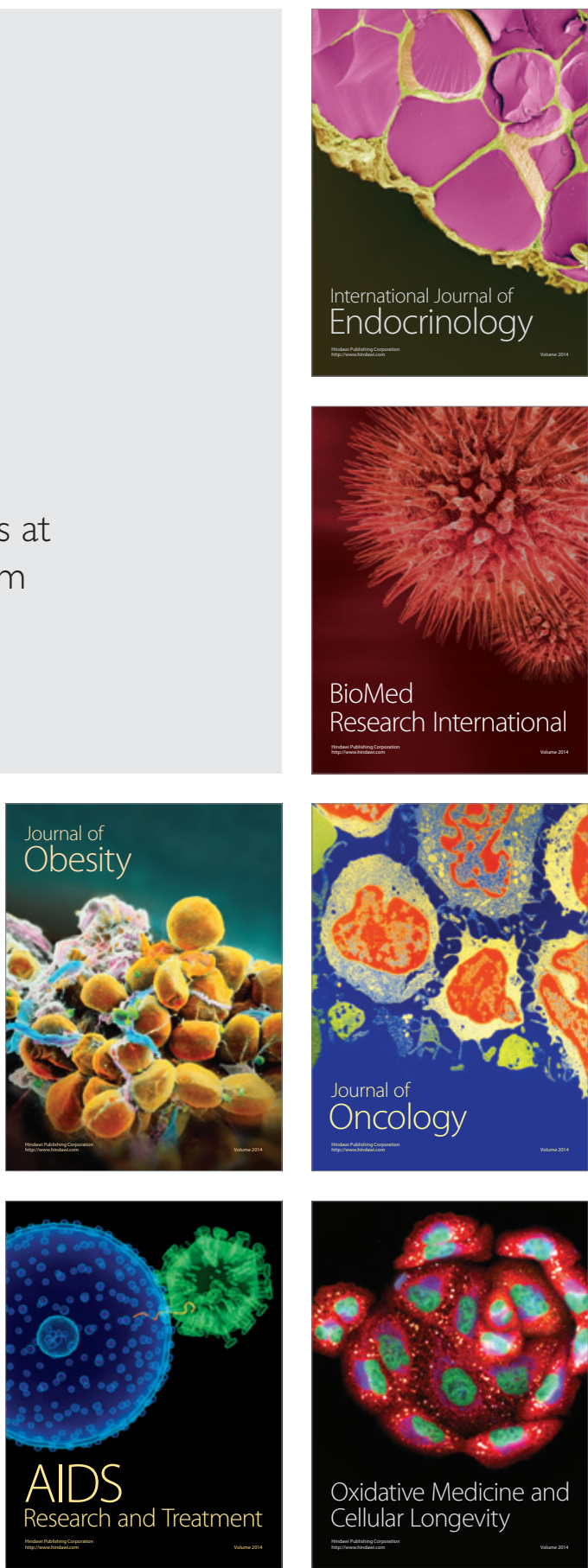